\title{
SELECTION ALONG CLINES IN THE LADYBIRD ADALIA BIPUNCTATA IN THE NETHERLANDS: A GENERAL MATING ADVANTAGE TO MELANICS AND ITS CONSEQUENCES
}

\author{
PAUL M. BRAKEFIELD \\ Department of Population and Evolutionary Biology, University of Utrecht, Padualaan 8 , \\ The Netherlands*
}

Received II.vii.83

\begin{abstract}
SUMMARY
The influence of non-random mating on the melanic polymorphism in Adalia bipunctata was investigated in the Netherlands. Study sites were along clines in melanic frequency. The phenotype frequencies among mating pairs (total $N=$ 3890 ) and non-mating insects were scored for each sample obtained during the spring mating period. The analysis of individual samples and of the data grouped into frequency classes provided no support for published findings from less homogeneous data of a frequency dependent mating system. Contingency table analyses for individual samples and data combined by site revealed that a mating advantage is gained by melanics. There was some evidence of heterogeneity between populations. No assortative mating was found for melanism or dry weight. An absence of any difference for mating insects in morph frequency between the sexes is not consistent with the operation of a female choice system as found by other workers for an English population. The analysis of frequency data for the offspring of mating populations collected as pupae provided strong evidence that the mating advantage gained by melanics is reflected in an increase in melanic frequency in the following adult generation. Mean estimates of selective advantage (non-melanics $=1$ ) for the mating advantage and for the adult to pupal period are 1.16 and $1 \cdot 10$, respectively. It is argued that the data give strong support for Lusis's (1961) suggestion that increases in melanic frequency observed during the summer in Berlin (and in the Netherlands) can be explained by more frequent mating of melanics as a result of the effects of thermal melanism.
\end{abstract}

\section{INTRODUCTION}

The two-spot ladybird beetle Adalia bipunctata is polymorphic for several non-melanic and melanic forms. These are controlled by a multiple allelic series with melanics dominant to non-melanics (Lus, 1928, 1932). Evidence has been obtained that the polymorphism is influenced by non-random mating involving a differential contribution by certain phenotypes in the whole population to the mating group (within mating pairs there is no assortment; non-melanics and melanics combine at random). Several workers have compared the frequencies of morphs among mating pairs with those in whole samples. Lusis (1961) working in Riga and Moscow found an excess of melanics in mating pairs. Creed (1975) found no such effect for smaller data sets obtained by himself in Britain and Western Europe and by Meissner $(1907 a, b ; 1909)$ in Potsdam. However, the method of analysis used by Lusis and Creed is unsatisfactory (Muggleton, 1979;

* Present address: Department of Biological Sciences, University of Exeter, Perry Road, Exeter, EX4 4QG 
Majerus, O'Donald and Weir, 1982a). Muggleton's (1979) analysis of Meissner's data and of his own for widely scattered populations in Britain suggested frequency dependent mating of the non-melanic and melanic forms. However, some samples used in his regression analysis included only small numbers of mating pairs. Of these samples, four key ones having the highest melanic frequencies involved a total of eighteen pairs (Muggleton's fig. 1 and table 2). Furthermore, the exclusion of samples with no melanics among the mating insects may have introduced bias. O'Donald and Muggleton (1979) applied models of mating preference to Muggleton's data grouped into frequency classes and obtained globally stable equilibrium frequencies.

Data collected by Majerus, O'Donald and Weir (1982a) for a single population at Keele in England showed an excess of males (but not of females) of the two common melanic morphs in mating pairs. Their laboratory population cage and mating choice experiments using a stock from Keele supported the existence of preferential mating by female choice. This resulted in a strong frequency dependent advantage for melanic males at the lowest frequencies used in population cages. Majerus, O'Donald and Weir $(1982 b)$ report on further selection experiments which demonstrated that the female mating preference is under genetic control.

This paper examines more homogeneous and extensive mating data for individual phenotypes for deviations from random mating. The location of study sites along clines in the Netherlands enables the relationship between such deviations and melanic frequency to be analysed in a more rigorous way. The samples were obtained in conjunction with an investigation of climatic selection and the dynamics of the polymorphism (Brakefield, $1984 a, b)$.

Non-random mating in a population can have a profound effect on its genetic composition. The consequences of non-random mating for the composition of the following generation in populations in the Netherlands are revealed by analysis of frequency data for the offspring of mating insects collected as pupae.

\section{THE STUdy AREA}

The seventy-five study sites were villages, towns or cities in the Netherlands and northern Belgium (Brakefield, 1984a, fig. 1). Three of the largest towns or cities which were sampled extensively were divided into two sites. Most sites (numbers 1 to 57) were on four transects of 90 or $120 \mathrm{~km}$ in length; two running eastwards from the coast of central Holland and two bisecting these from north to south. The transects traversed an area between a region of low, and one of high melanic frequency. Clines occur on each transect; the steepest parts involving increases in melanic frequency over about $20 \mathrm{~km}$ from 1-10 per cent to $50-55$ per cent (Brakefield, $1984 a$, figs 6 and 7).

\section{Material AND methods}

Samples of $\boldsymbol{A}$. bipunctata were collected from each site between 1978 and 1982. The sampling of adults covered the whole of the mating period at the main sites. Only those samples taken after emergence from hibernation in late April and prior to commencement of recruitment of the next adult 
generation in June (see Brakefield, 1984a) are analysed in this study. During the peak mating period in May substantial proportions of $A$. bipunctata were mating at any one time (up to 44 per cent). This proportion was lower earlier and later in the mating season and there is evidence that preferred mating habitats are shrubs rather than trees. A high sampling intensity was obtained in most shrub habitats where many samples represent counts rather than collections. Details of the population biology of $A$. bipunctata at the study sites are given by Brakefield (1984a).

In the Netherlands only three morphs of $A$. bipunctata are abundant; all others together comprising less than 1 per cent of a population. The three morphs are the non-melanic red typica and the melanic quadrimaculata and sexpustulata with four and six red spots respectively. The phenotype of the male and female of each mating pair and of all non-mating insects was recorded. The dry weight of selected samples of mating beetles was determined following drying to constant weight at $60^{\circ} \mathrm{C}$.

The mating data for each site are grouped in three different ways for analysis:

(a) Individual samples collected in discrete habitats, usually of single plant species, on separate sampling occasions (details in Brakefield, $1984 a$ ). Their analysis includes only those with a minimum of ten mating pairs;

(b) Samples for separate years combined by site;

(c) All samples combined by site (overall).

An index for deviation from random mating is obtained by calculating the natural logarithm of the following cross product ratio (after Muggleton, 1979):

$$
\frac{\text { total no. of non-melanic insects }}{\text { total no. of melanic insects }} \times \frac{\text { no. of melanics mating }}{\text { no. of non-melanics mating }} .
$$

Values of greater than one indicate an excess of melanics among mating insects and those of less than one indicate an excess of non-melanics.

The statistical analysis of contingency table data by chi-square follows the methods described by Everitt (1977). Cochran's method of calculating the test statistic of $Y$ is used for combining the information from a number of $2 \times 2$ tables and to make an overall test of the association between morph class and mating status (mating/non-mating).

Thirteen sites from the transects were selected for collection of sequential samples of pupae in 1980 and 1981 (see Brakefield, 1984b). Adults emerged from the pupae in the laboratory were scored later for morph class. Only the data for the first generation of pupae are analysed in this paper.

\section{Results}

\section{(i) Non-random mating of melanics and non-melanics}

The pooled data for sites from which at least ten mating pairs were obtained are given in the appendix. Fig. 1 suggests that there is a tendency towards positive values for the cross product ratio calculated for individual samples. Application of the binomial test shows that there is a significant deviation from an equal probability of values of each sign $(P<0.025$ for 
a) $\min .10$ pairs

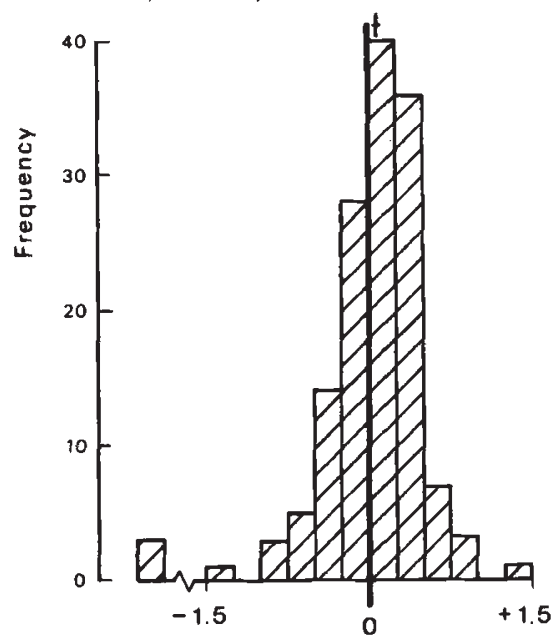

b) 25 prs.

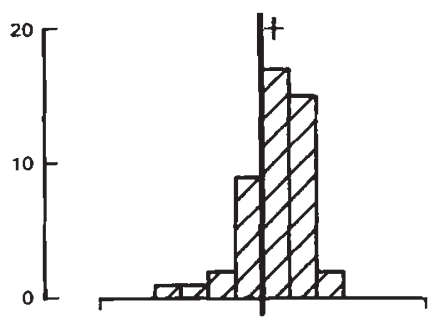

c) $40 \mathrm{prs}$.

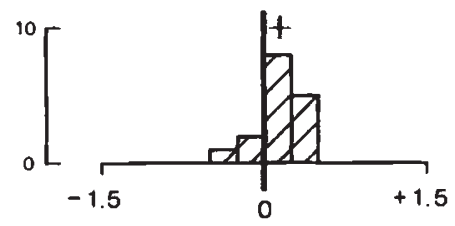

Ln. cross product ratio

FIG. 1. Frequency distributions for values of the natural logarithm of the cross product ratio of the melanic and non-melanic morph classes of Adalia bipunctata in the mating part of the sample and the whole sample for differing minimum numbers of mating pairs. Positive values indicate an excess of melanics in the mating pairs, negative values indicate an excess of non-melanics. Bars show mean \pm 95 per cent confidence limits.

each data set in fig. 1). The values for Cochran's $Y$ statistic given in table 1 confirm that there is an overall excess of melanics in the mating insects. A three-way G-test analysis (Sokal and Rohlf, 1981) was performed on each data set with factors of sample, mating status and frequency of the morph classes. The $G$ value for the complete 3 -way interaction is non-significant in each case $(P>0.25)$ and it can be concluded that the interaction between mating status and frequency is not heterogeneous between samples. There is also no evidence for a regression of cross product ratio on sampling date, either for all individual samples $(b=-0.0005, F=0.10, P>0.25)$ or for those from sites where at least ten samples were obtained $(P>0.1$ for each site). Furthermore, the cross product ratio is not correlated with the proportion of mating insects in the whole sample ( $r=-0.05$ for all samples).

When the data for all samples are combined by site the deviation from random mating of the morph classes remains highly significant (table 1). However, a $G$-test analysis provides some evidence for a 3-way interaction (minimum of 10 pairs: $G=35 \cdot 74, \mathrm{df}=31, P>0 \cdot 1$; 50 pairs: $G=17 \cdot 16$, $\mathrm{df}=9, P<0.05 ; 100$ pairs: $G=12.47, \mathrm{df}=6, P$ approaches 0.05 ). This suggests that the association between mating status and frequency may not be independent of site. Table 2 shows that sites 31,32 and 54 each exhibit significant deviations from random mating and show positive mean values for the cross product ratios for individual samples and for separate years. Table 1 suggests that these sites in large measure produce the highly significant overall values for Cochran's $Y$ statistic. A 3-way $G$-test analysis excluding site 32 , which shows the most significant deviation, yields much reduced values of $G$ for the complete interaction $(G=7 \cdot 63$, df $=5$ and $G=11 \cdot 53, \mathrm{df}=8$ with $P>0 \cdot 1$ for each value). 
TABLE 1

Values of $\mathrm{Y}$ statistic obtained from application of Cochran's method to detect systematic differences in the proportion of melanic Adalia bipunctata in the mating and non-mating parts of individual samples and of the combined samples for each site

\begin{tabular}{|c|c|c|c|c|c|c|}
\hline & & Samples & & & Sites & \\
\hline $\begin{array}{l}\text { minimum no. } \\
\text { mating pairs: }\end{array}$ & 10 & 25 & 40 & 10 & 50 & 100 \\
\hline All data & $4 \cdot 53^{* * *}$ & $4 \cdot 21^{* * * *}$ & $3 \cdot 07^{* *}$ & $4 \cdot 66^{* * *}$ & $4 \cdot 20^{* * * *}$ & $4 \cdot 38^{* * *}$ \\
\hline $\begin{array}{l}\text { Excluding: } \\
\text { sites } 31,32 \text { \& } 54\end{array}$ & $2 \cdot 36^{*}$ & $2.69^{*}$ & $2 \cdot 56^{*}$ & 1.87 & 1.34 & 1.48 \\
\hline
\end{tabular}

* $P<0.05$; ** $P<0.01$; *** $P<0.001$.

The data for individual samples displayed in fig. 1 show no regression of the cross product ratio on arcsin transformed percentage frequency of melanics (minimum of 10 pairs: $b=-0.0003, F=0.01 ; 25$ pairs: $b=+0.004$, $F=1 \cdot 39$, 40 pairs: $b=-0.004, F=0.52$ with $P>0.25$ for each value). Examination of table 2 shows that sites 31 and 32 which exhibit an excess of melanics in mating pairs have high melanic frequencies. Sites 33 and 38 with similarly high frequencies show no deviation from random mating whilst sites 25 and 54 (a single sample) with lower frequencies of melanics also show some evidence of a mating advantage for melanics. When all the data are grouped into frequency classes in the same way as in Muggleton's (1979) study the absence of any frequency dependent relationship is emphasised (table 3). Each frequency class shows a positive cross product ratio and in three of the six classes with large sample sizes the excess of melanics in mating insects is significant.

The data for the phenotype of males and females in mating pairs (see appendix) have been compared to examine whether the mating advantage is associated with a particular sex. In this case an excess of melanics is expected in the mating insects of one sex over the other. This analysis assumes that there is no difference in morph class frequencies between the sexes in a population as a whole. There are no data in support of such a difference (Majerus, O'Donald and Weir, 1982a, table 4(i)). Table 4 shows that the mating advantage for melanics is not associated with a particular sex either for the individual samples or for the sites (including those exhibiting significant overall deviations). There is thus no evidence for the operation of a female choice mechanism.

\section{(ii) Mating advantages and the individual phenotypes}

The frequencies of the three phenotypes in mating pairs were compared with those in non-mating insects at the main sites by use of a partitioned contingency chi-squared analysis. The results are presented in table 5. At sites 31 and 32 the mating advantage is much stronger and only significant for the quadrimaculata melanic morph. In contrast, the data for sites 4 and 54 suggest that whilst there is an advantage it is gained by the sexpustulata melanic morph. However, only a single sample was obtained at site 54 and the low melanic frequency, particularly at site 4 , indicates that sampling 


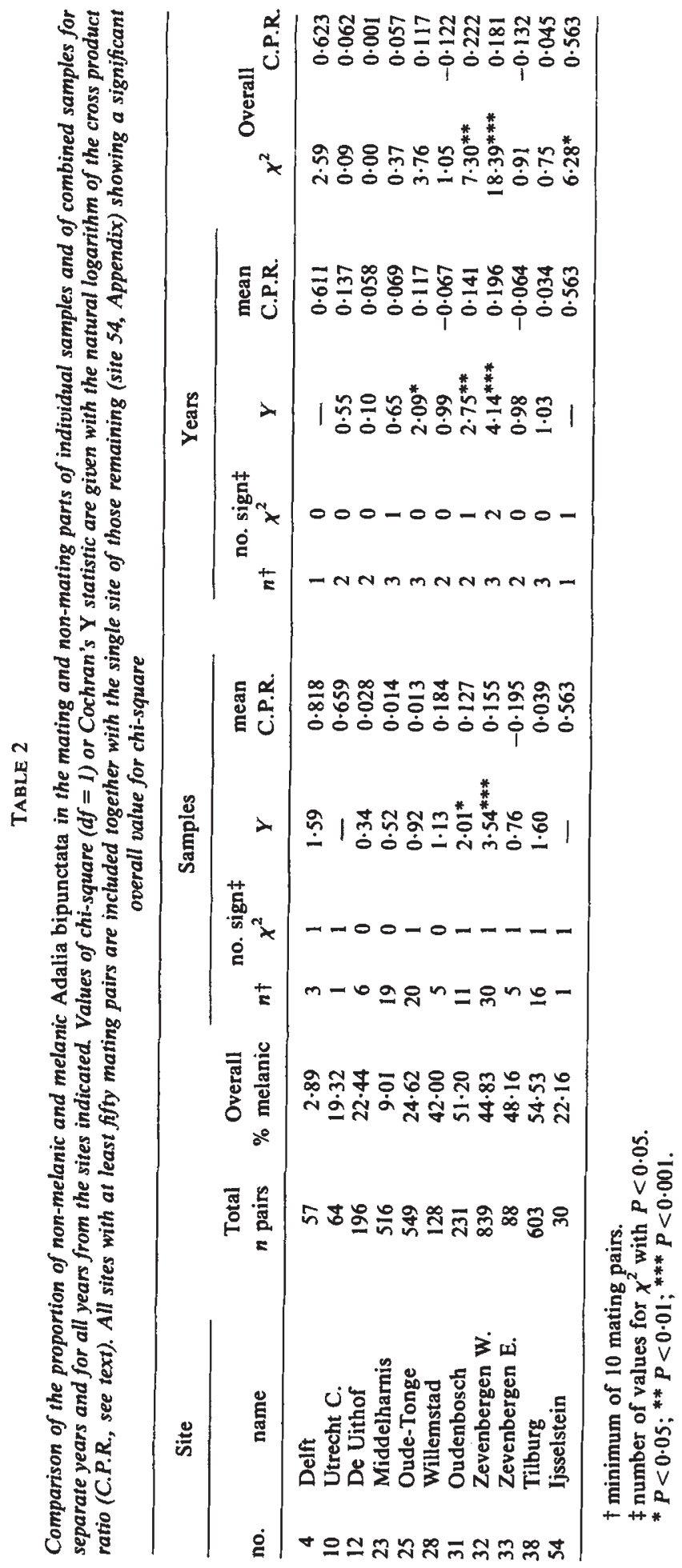


TABLE 3

Numbers of non-melanic and melanic Adalia bipunctata in the mating and non-mating parts of samples for each of seven frequency classes. Comparisons by chi-squared test and values of the cross product ratio (C.P.R., see text) are given for each class

\begin{tabular}{|c|c|c|c|c|c|c|}
\hline \multirow{2}{*}{$\begin{array}{c}\text { Melanic } \\
\text { frequency } \\
\text { in whole } \\
\text { sample }(\%)\end{array}$} & \multicolumn{2}{|c|}{$\begin{array}{l}\text { Number of } \\
\text { mating insects }\end{array}$} & \multicolumn{2}{|c|}{$\begin{array}{c}\text { Number of } \\
\text { non-mating insects }\end{array}$} & \multirow[b]{2}{*}{$\log _{e}$ C.P.R. } & \multirow[b]{2}{*}{$\mathrm{Chi}^{2}$} \\
\hline & non-melanic & melanic & non-melanic & melanic & & \\
\hline $0-9.9$ & 1205 & 109 & 5217 & 418 & 0.097 & $1 \cdot 17$ \\
\hline $10 \cdot 0-19.9$ & 463 & 93 & 2739 & 535 & 0.024 & 0.05 \\
\hline $20.0-29.9$ & 1207 & 439 & 4812 & 1543 & 0.099 & $4.01 *$ \\
\hline $30.0-39.9$ & 105 & 65 & 656 & 320 & 0.202 & 1.93 \\
\hline $40 \cdot 0-49 \cdot 9$ & 1160 & 1070 & 4649 & 3633 & 0.130 & $12.04^{* * *}$ \\
\hline $50.0-59.9$ & 813 & 1039 & 3528 & 3983 & 0.098 & $5 \cdot 46^{*}$ \\
\hline $60 \cdot 0-69 \cdot 9$ & 3 & 9 & 29 & 46 & $(0.557)$ & 0.83 \\
\hline
\end{tabular}

${ }^{*} P<0.05 ;{ }^{* * *} P<0.001$.

\section{TABLE 4}

Comparison of the proportion of non-melanic and melanic Adalia bipunctata in the males and females of mating pairs in individual samples and the combined samples from each site. The table gives the number of significant $(\mathrm{P}<0.05)$ values of chi-square for individual comparisons, the overall Cochran's Y statistic and the mean cross product ratio (a positive value indicates a higher proportion of melanics in males, see text)

\begin{tabular}{lcccc}
\hline & \multicolumn{2}{c}{ Samples } & \multicolumn{2}{c}{ Sites } \\
\hline minimum no. pairs & 25 & 40 & 50 & 100 \\
no. of comparisons & 47 & 16 & 10 & 7 \\
no. of significant $\chi^{2}$ & 2 & 1 & 0 & 0 \\
Cochran's Y & 0.15 & 0.58 & 0.46 & 0.56 \\
mean $\log _{e}$ C.P.R. & -0.053 & -0.005 & -0.048 & -0.011 \\
\hline
\end{tabular}

\section{TABLE 5}

Comparison by use of a partitioned chi-squared test (see Everitt, 1977) of the frequencies of the typica (typ), sexpustulata (sexp) and quadrimaculata (quad) phenotypes in the mating and non-mating parts of the combined samples of Adalia bipunctata from the sites indicated (minimum $=50$ mating pairs plus site 54 , see table 2)

\begin{tabular}{|c|c|c|c|c|}
\hline \multicolumn{2}{|r|}{ Site } & \multirow{2}{*}{$\begin{array}{l}x^{2} \\
\operatorname{typ} \times \operatorname{sexp} \\
(\mathrm{df}=1)\end{array}$} & \multirow{2}{*}{$\begin{array}{c}\chi^{2} \\
\text { typ }+\operatorname{sexp} \times \text { quad } \\
(\mathrm{df}=1)\end{array}$} & \multirow{2}{*}{$\begin{array}{c}\text { Overall } \\
\chi^{2} \\
(\mathrm{df}=2)\end{array}$} \\
\hline no. & name & & & \\
\hline 4 & Delft & $8.98^{* *}$ & $0 \cdot 38$ & $9 \cdot 36^{* * *}$ \\
\hline 10 & Utrecht C. & $2 \cdot 44$ & 0.78 & $3 \cdot 22$ \\
\hline 12 & De Uithof & $1 \cdot 07$ & 0.63 & $1 \cdot 70$ \\
\hline 23 & Middelharnis & 0.44 & 0.08 & 0.52 \\
\hline 25 & Oude-Tonge & $2 \cdot 56$ & $1 \cdot 57$ & $4 \cdot 13$ \\
\hline 28 & Willemstad & 0.08 & $1 \cdot 15$ & $1 \cdot 23$ \\
\hline 31 & Oudenbosch & 0.44 & $9 \cdot 05^{* *}$ & $9 \cdot 48^{* *}$ \\
\hline 32 & Zevenbergen $\mathrm{W}$. & $2 \cdot 57$ & $17 \cdot 39^{* * *}$ & $19.95^{* * *}$ \\
\hline 33 & Zevenbergen $\mathrm{E}$. & 0.69 & 0.30 & 1.00 \\
\hline 38 & Tilburg & 0.95 & $0 \cdot 11$ & 1.06 \\
\hline 54 & Ijsselstein & $7 \cdot 17^{* *}$ & 1.07 & $8 \cdot 24^{*}$ \\
\hline
\end{tabular}

${ }^{*} P<0.05$ ** $^{* *}<0.01 ;{ }^{* * *} P<0.001$. 
errors are very large especially for the least common sexpustulata. The results in table 5 reveal no significant effects at the other main sites.

There is only evidence of assortative mating at one of the main sites (table 6). The analyses for sites 31 and 32 and when all sites are considered do not indicate any deviation from random pairing amongst mating insects. Similarly a partitioned chi-squared analysis of the sixteen individual samples of at least forty mating pairs yields only one significant $(P<0.05)$ overall value for chi-square.

\section{TABLE 6}

Comparison by use of a partitioned chi-squared test (see Everitt, 1977) of the frequencies of the typica (typ), sexpustulata (sexp) and quadrimaculata (quad) phenotypes in the males and females of the combined samples of mating pairs of Adalia bipunctata from the sites indicated (minimum = 100 mating pairs, see table 2). Values of chi-square for individual orthogonal comparisons have $I d f$ and the overall values, $4 d f$

\begin{tabular}{|c|c|c|c|c|c|c|c|}
\hline \multirow[b]{2}{*}{ Comparison ${ }^{\dagger}$} & \multicolumn{7}{|c|}{ Site no. } \\
\hline & 12 & 23 & 25 & 28 & 31 & 32 & 38 \\
\hline $\begin{array}{l}\text { quad \& sexp females } \times \text { quad } \\
\& \text { sexp males }\end{array}$ & 0.70 & $0 \cdot 20$ & $0 \cdot 16$ & $1 \cdot 03$ & 0.02 & 0.03 & 0.55 \\
\hline $\begin{array}{l}\text { typ \& mel females } \times \text { quad } \\
\& \text { sexp males }\end{array}$ & 0.80 & 0.74 & 0.39 & 0.01 & 0.05 & 2.44 & 0.00 \\
\hline $\begin{array}{l}\text { quad \& sexp females } \times \text { typ } \\
\& \text { mel males }\end{array}$ & $6 \cdot 20^{*}$ & 0.64 & 0.49 & 0.30 & 1.25 & 0.42 & 1.37 \\
\hline $\begin{array}{l}\text { typ \& mel females } \times \text { typ } \\
\& \text { mel males }\end{array}$ & $2 \cdot 94$ & 0.72 & $2 \cdot 00$ & 0.31 & $2 \cdot 84$ & 0.14 & $5 \cdot 64^{*}$ \\
\hline Overall & $10 \cdot 64^{*}$ & $2 \cdot 30$ & 3.04 & 1.65 & $4 \cdot 16$ & $3 \cdot 04$ & $7 \cdot 56$ \\
\hline
\end{tabular}

$\dagger$ mel $($ melanic $)=$ quad + sexp.

${ }^{*} P<0.05$.

\section{(iii) Analysis of selective advantage}

Table 7 gives the results for sites in each year of a comparison of frequency data for the mating adult population and those for their offspring collected as pupae. Series of estimates of the selective advantage of melanics (non-melanics $=1$ ) are given for the mating against the whole adult population and for the pupal generation against the combined pupal and adult generations. The estimates are therefore not independent but a useful comparison can be made. Twelve of the eighteen data sets give estimates of selective advantage in favour of melanics for both series. There are significantly more cases for which both estimates indicate a selective advantage gained by melanics than a selective disadvantage (sign test: $P=0.019$ ). Five of the six larger data sets give estimates both in favour of melanics $(P>0 \cdot 1)$. Values of Cochran's $Y$ statistic for the comparisons of mating and non-mating insects and for adult and pupal generations are highly significant (18 data sets: $Y=4.23$ and $7 \cdot 35$, respectively; 6 sets: $Y=4.02$ and 5.73 with $P<0.001$ for each value). These values are much reduced for the comparisons of mating adults and pupae (18 sets: $Y=2.61, P<0.01$; 6 sets: $Y=1 \cdot 47, P>0 \cdot 1)$. Thus, although there is no formal correlation between the two series of estimates for selective advantage $(P>0.25)$, the mating adults and pupae show a more similar composition of melanics and 


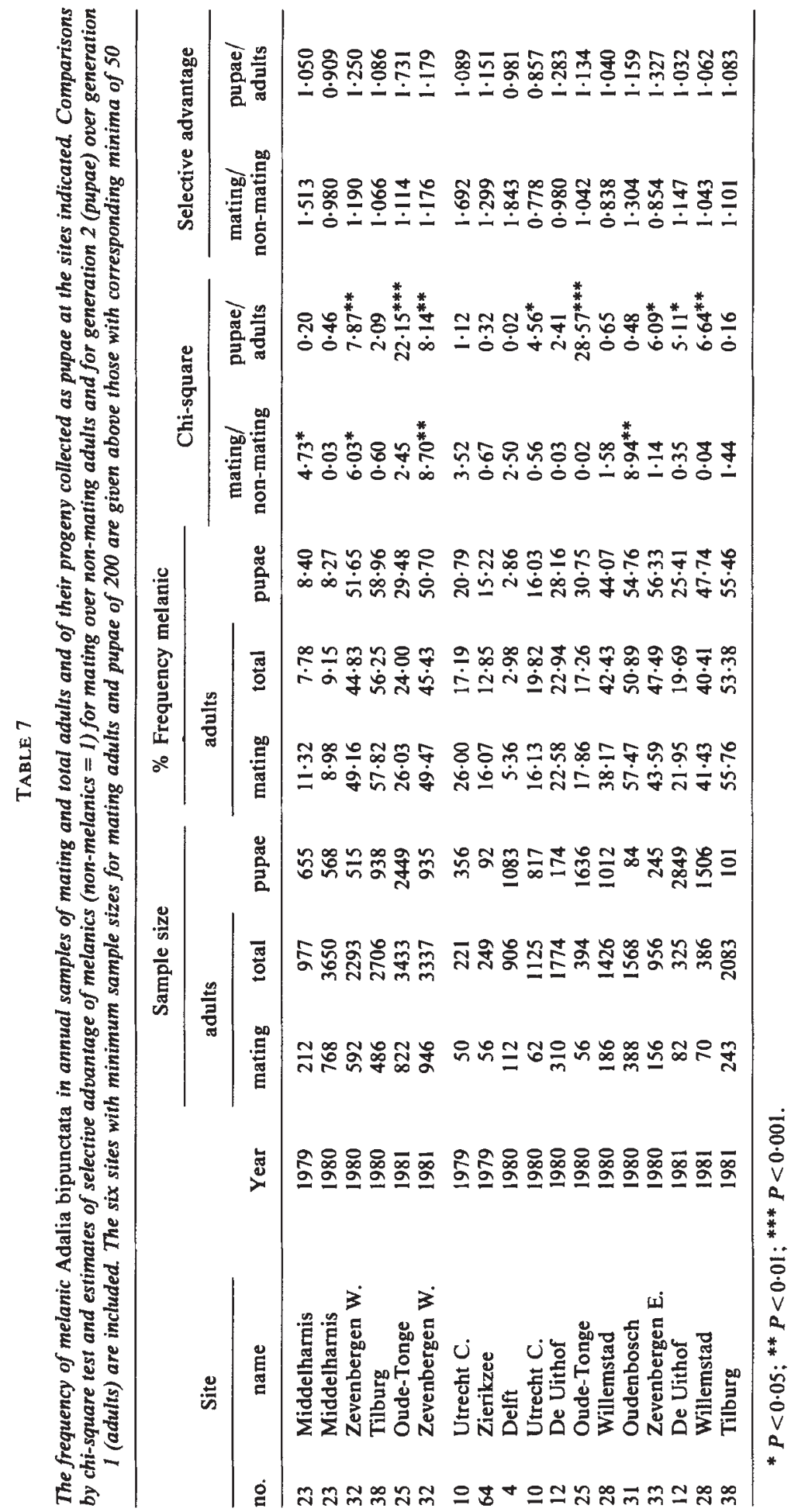


non-melanics to each other than they do to the non-mating and whole adult populations, respectively. The means of the series of estimates of selective advantage calculated using the data for mating insects and for pupae, respectively are for all data sets, 1.16 and 1.10 and for the six larger sets, $1 \cdot 17$ and $1 \cdot 11$. Although these results should be interpreted with caution, for example because of possible errors introduced by differential timing of reproduction (Brakefield, 1984b), they do suggest that the mating advantage gained by melanics is reflected in an increase in melanic frequency in the following adult generation.

\section{Discussion}

This study provides no evidence that mating is assortative; pairings between the non-melanic typica and melanic quadrimaculata and sexpustulata do not deviate from the frequencies expected under random pairing among the mating insects. This supports the findings of Muggleton (1979) and Majerus, O'Donald and Weir (1982a). The latter workers did detect assortative mating amongst typica and another non-melanic, annulata, which is present only at low frequencies in the Netherlands.

The measurements of dry weight of mating insects from five populations have been examined for assortative mating. Female $A$. bipunctata are larger than males but there are no differences in size between the most numerous phenotypes (Brakefield, 1984a). The combined samples from one population show a weak positive correlation between the weights of males and females in copula whilst those from the other populations show no correlation (table 8 ). There are changes in weight within the mating season (Brakefield, 1984a)

TABLE 8

Overall product moment correlation coefficients ( $\mathrm{r}$ ) for dry weights of mating pairs of Adalia bipunctata at the sites indicated in 1980. Weighted means $\left(\mathrm{r}_{\mathrm{w}}\right)$ and tests of homogeneity $\left(\mathrm{X}^{2}, d f\right.$ in parentheses, see Sokal and Rohlf, 1981) are given for comparisons of the correlation coefficients calculated for separate sampling periods during the mating season

\begin{tabular}{|c|c|c|c|c|c|c|}
\hline \multicolumn{2}{|r|}{ Site } & \multirow{2}{*}{$\begin{array}{l}\text { No. of } \\
\text { pairs }\end{array}$} & \multirow{2}{*}{$\begin{array}{c}r \\
\text { raw data }\end{array}$} & \multirow{2}{*}{$\stackrel{r}{\log (\text { data })}$} & \multirow{2}{*}{$\begin{array}{c}r_{w} \\
\text { (raw data) }\end{array}$} & \multirow[b]{2}{*}{$X^{2}$} \\
\hline no. & name & & & & & \\
\hline 12 & De Uithof & 119 & -0.069 & -0.058 & -0.147 & $11 \cdot 73(4)^{*}$ \\
\hline 28 & Willemstad & 27 & 0.013 & -0.037 & 0.079 & $0.76(1)$ \\
\hline 31 & Oudenbosch & 180 & 0.136 & $0 \cdot 104$ & -0.047 & $1 \cdot 67(4)$ \\
\hline 32 & Zevenbergen $\mathbf{W}$. & 68 & -0.177 & $-0 \cdot 048$ & - & - \\
\hline 38 & Tilburg & 222 & $0.139^{*}$ & $0.161^{*}$ & 0.111 & $7 \cdot 59(5)$ \\
\hline
\end{tabular}

$* P<0.05$.

and therefore the correlation coefficients for successive subsamples from each population have been analysed. There is then no suggestion of assortative mating for weight (table 8). These results contrast with examples of positive correlations found in at least some populations of other species of beetle (McCauley and Wade, 1978; McLain, 1982a, b; McCauley, 1981).

My data show that a mating advantage is gained by melanics. The absence of any difference between the sexes in the frequency of melanics and non-melanics in mating insects argues against the operation of any preference mechanism in the Netherlands. A similar lack of such a difference 
is also apparent in the grouped data of Muggleton (1979) and Lusis (1961). The data obtained by Majerus, O'Donald and Weir (1982a) at Keele show a highly significant excess of melanic males but not females in mating insects. Their data were collected in early August and therefore may have involved overlapping generations (see Brakefield, 1984a). This could have introduced bias into the samples if, for example, there were differences in melanic frequency between the generations and different proportions of the sexes in each generation were sexually mature or receptive. However, the results of Majerus, O'Donald and Weir's $(1982 a, b)$ population cage and mating choice experiments are consistent with the observed deviation from random mating at Keele. They have interpreted their results as evidence of females of all phenotypes exhibiting a preference for melanic males. Populations of $A$. bipunctata are expected to be polymorphic for genes controlling female preference. They indicate that the proportion of females exhibiting preference will depend on several factors. It is possible that the genes for preference are at too low a frequency in the Netherlands for their effect to be detected in even the large samples obtained here.

Lusis (1961) proposed that an increase in melanic frequency observed by Timoféeff-Ressovsky (1940) during each of a number of summers in Berlin could be explained by more frequent mating of melanics. The present study provides strong evidence that this type of process is occurring in at least some populations in the Netherlands. Lusis further suggested that melanics exhibit a more efficient absorption of solar radiation which results in the more intense mating activity. Findings of an earlier timing of reproduction by melanics in the Netherlands (Brakefield, 1984b) and examples of negative correlations between melanic frequency and sunshine levels in Britain (Muggleton, Lonsdale and Benham, 1975) and the Netherlands (Brakefield, 1984a; but see Brakefield, 1984b) have provided support for the theory of thermal melanism in $A$. bipunctata. These observations suggest that the general mating advantage gained by melanics in the Netherlands can be explained by a higher encounter rate of potential mates by melanics of each sex due to the effects of thermal melanism. There is some evidence for variation between populations in the degree of mating advantage gained by melanics. Two populations which are only $8 \mathrm{~km}$ apart show particularly strong deviations from random mating. Many factors, including population density, habitat type (e.g., shaded trees versus more open shrubs) and climatic conditions on sampling dates, are likely to contribute to such variability (see also Brakefield, 1984a, b).

An apparent general mating advantage for melanics could result if melanics remain in copula for longer periods of time than non-melanics. Data are needed to adequately test this explanation. However, the observed relationship between a mating advantage gained by melanics and an increase in their frequency between generations argues against the advantage being an artefact. Thermal melanism might in any case be predicted to result in shorter rather than longer durations of copulation for melanics.

It has been proposed that a frequency dependent mating system provides the mechanism by which the polymorphism in A. bipunctata is maintained (Muggleton, 1979; O'Donald and Muggleton, 1979). This cannot be the case in the Netherlands where the differential contribution by melanics to the mating population does not vary as a function of their frequency or change in a consistent manner along the clines. An alternative mechanism 
for maintaining the polymorphism may involve cyclical selection (TimofeeffRessovsky and Svirezhev, 1966; and see Muggleton, 1978). The significance of the increase in melanic frequency observed during the first annual generation in the Netherlands will be discussed in relation to seasonal changes in selection in a following paper.

Acknowledgments. The main body of this research was carried out on a Royal Society European Exchange Fellowship. I am most grateful to Professor W. Scharloo at Utrecht for providing facilities. I thank Mrs B. Vermeulen for typing the manuscript.

\section{REFERENCES}

BRAKEFIELD, P. M. 1984a. Ecological studies on the polymorphic ladybird Adalia bipunctata in The Netherlands. I. Population biology and geographical variation of melanism. $J$. Anim. Ecol., (in press).

BRAKEFIELD, P. M. 1984b. Ecological studies on the polymorphic ladybird Adalia bipunctata in The Netherlands. II. Population dynamics, differential timing of reproduction and thermal melanism. J. Anim. Ecol., (in press).

CREED, E. R. 1975. Melanism in the two spot ladybird: the nature and intensity of selection. Phil. Trans. Roy. Soc. Lond. B., 190, 135-148.

EVERITT, B. S. 1977. The Analysis of Contingency Tables. Chapman and Hall, London.

LUS, J. J. 1928. On the inheritance of colour and pattern in lady beetles Adalia bipunctata L. and Adalia decempunctata L. Izv. Byuro. Genet. Leningrad, 6, 89-163.

LUS, J. J. 1932. An analysis of the dominance phenomenon in the inheritance of the elytra and pronotum colour in Adalia bipunctata. Trudy Lab. Genet., 9, 135-162.

LUSIS, J. J. 1961. On the biological meaning of colour polymorphism of lady-beetle Adalia bipunctata L. Latv. Ent., 4, 3-29.

MAJERUS, M. E. N., O'DONALD, P. AND WEIR, J. 1982a. Evidence for preferential mating in Adalia bipunctata. Heredity, 49, 37-49.

MAJERUS, M. E. N., O'DONALD, P AND WEIR, J. 1982b. Female mating preference is genetic. Nature (London), 300, 521-523.

McCAUlEY, D. E. 1981. Application of the Kence-Bryant model of mating behaviour to a natural population of soldier beetles. Am. Nat., 117, 400-402.

McCAULEY, D. E. AND WADE, M. J. 1978. Female choice and the mating structure of a natural population of the soldier beetle, Chauliognathus pennsylvanicus. Evolution, 32, 771-775.

McLAIN, D. K. 1982a. Behavioural and morphological correlates of male dominance and courtship persistence in the blister beetle Epicauta pennsylvanica (Coleoptera: Meloidae). Am. Midl. Nat., 107, 396-403.

McLAIN, D. K, 1982b. Density dependent sexual selection and positive phenotypic assortative mating in natural populations of the soldier beetle, Chauliognathus pennsylvanicus. Evolution, 36, 1227-1235.

MEISSNER, O. 1907a. Die relative Häufigkeit der Varietäten von Adalia bipunctata L. in Potsdam (1906). Z. wiss. InsektBiol, 3, 12-20, 39-45.

MEISSNER, O. 1907b. Die relative Häufigkeit der Varietäten von Adalia bipunctata L. in Potsdam (1907). Z. wiss. InsektBiol, 3, 309-313, 334-344, 369-374.

MEISSNER, O. 1909. Die relative Häufigkeit der Varietäten von Adalia bipunctata L. in Potsdam (1908). Z. wiss. InsektBiol., 5, 231-242.

MUGGleton, J. 1978. Selection against the melanic morphs of Adalia bipunctata (two-spot ladybird): a review and some new data. Heredity, 40, 268-290.

MUGGLETON, J, 1979. Non-random mating in wild populations of polymorphic Adalia bipunctata. Heredity, 42, 57-65.

MUGGLetON, J., LONSDALE, D. AND BENHAM, B. R. 1975. Melanism in Adalia bipunctata L. (Col., Coccinellidae) and its relationship to atmospheric pollution. J. appl. Ecol., 12, $451-464$.

SOKAL, R. R. AND ROHLF, F. J. 1981. Biometry (second edn). W. H. Freeman \& Co., San Francisco.

TIMOFEeff-Ressovsky, N. V. 1940. Zur Analyse des Polymorphismus bei Adalia bipunctata L. Biol. Zbl., 60, 130-137.

TIMOFEEFF-RESSOVSKY, N. V. AND SVIREZHEV, Y. M. 1966. Adaptation polymorphism in populations of Adalia bipunctata L. Problemy Kibern., 16, 136-146 (English translation: Probl. Cybern., 16, 161-174). 


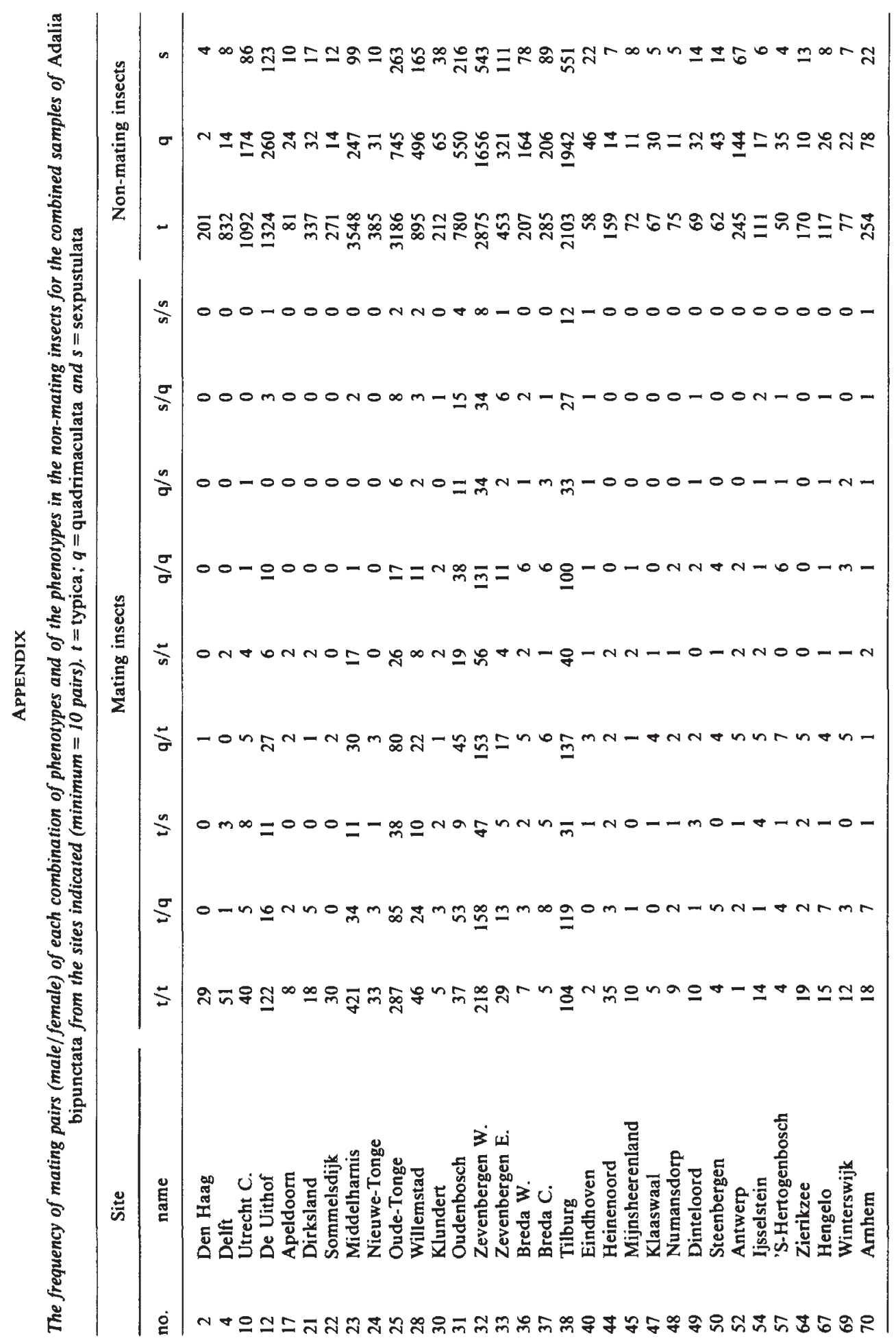

